\title{
The effect of artificial shrinkage and assisted hatching on the development of mouse blastocysts and cell number after vitrification
}

\author{
Hye Jin Kim', Ki Hwan Lee', Sung Baek Park², Young Bae Choi², Jung Bo Yang ${ }^{1}$ \\ 'Department of Obstetrics and Gynecology, Chungnam National University Hospital, Daejeon; ${ }^{2}$ Fertility Clinic, Mirae Ladies Hospital, Daejeon, Korea
}

\begin{abstract}
Objective: The goal of this study was to ascertain optimal assisted hatching (AH) method in frozen embryo transfer. We compared the effect of depending on whether mechanical or laser-AH was performed before or after the vitrification of embryo development rate and blastocyst cell numbers.

Methods: In order to induce superovulation, pregnant mare's serum gonadotropin followed by human chorionic gonadotropin were injected into 4- to 5-week-old female mice. 2-cell embryos were then collected by flushing out the oviducts. The Expanded blastocysts were recovered after the collected embryos were incubated for 48 hours, and were then subjected to artificial shrinkage (AS) and cross-mechanical AH (cMAH) or quarter-laser zona thinning-AH (qLZT-AH) were carried out using the expanded blastocysts before or after vitrification. After 48 hours of incubation, followed by vitrification and thawing $(\mathrm{V}-\mathrm{T})$, and blastocysts were fluorescence stained and observed.

Results: The rate of formation of hatched blastocysts after 24 and 72 hours of incubation was significantly higher in the AS/qLZT-AH/V-T group than in the other groups $(p<0.05)$. The cell number of the inner cell mass was higher in AS/N-T/non-AH and AS/N-T/cMAH groups than those of others $(p<0.05)$. In the control group, the number of trophectoderm and the total cell number were higher than in the AS-AH group $(p<0.05)$. Conclusion: The above results suggest that $\mathrm{AS}$ and $\mathrm{AH}$ in vitrification of expanded blastocysts lead to the more efficient formation of hatched blastocysts in mice.
\end{abstract}

Keywords: Artificial shrinkage; Assisted hatching; Mouse blastocyst; Vitrification

\section{Introduction}

Recent advances in in vitro culture techniques for human embryos have increased the rate of blastocyst formation. Therefore, in human assisted reproduction, blastocyst transfer is now preferred to the collection of a 3-day-old cleavage stage embryo using the routine method [1-3]. This is because it is possible to select a growth-arrested embryo at the 8-cell-stage, and because the transfer of 1 to 2 embry-

Received: Mar 20, 2015 · Revised: Jul 13, 2015 · Accepted: Aug 7, 2015 Corresponding author: Jung Bo Yang

Department of Obstetrics and Gynecology, Chungnam National University Hospital, 282 Munhwa-ro, Jung-gu, Daejeon 35015, Korea

Tel: +82-42-280-7219 Fax:+82-42-280-7264 E-mail:yangjb@cnuh.co.kr

This is an Open Access article distributed under the terms of the Creative Commons Attribution Non-Commercial License (http://creativecommons.org/licenses/by-nc/3.0/) which permits unrestricted non-commercial use, distribution, and reproduction in any medium, provided the original work is properly cited. os with a healthy trophectoderm (TE) and inner cell mass (ICM), increases the rates of pregnancy and implantation and reduces the incidence of multiple pregnancies [4-6]. The possibility of cryopreserving residual embryos 5 days after embryo transfer increases the likelihood of pregnancy while reducing the time, monetary, and physical burdens of patients struggling with infertility. Multiple studies have explored ways of increasing the rates of viability and hatching of cryopreserved and thawed blastocysts [6-9].

The cryopreservation of blastocysts using vitrification has been associated with a lower survival rate than observed for fresh embryos, due to the intracellular and extracellular formation of ice crystals caused by incomplete dehydration in the watery environment of the blastocoel cavity and by mixing with vitrifying solution during dehydration [9-11]. Moreover, the hatching rate has been found to be decreased by zona hardening, which results from in vitro culture and 
thawing $[9,12-14]$. The above factors reduce the pregnancy rate in human in vitro fertilization/embryo transfer [15-17]. The introduction of artificial shrinkage (AS) and vitrification to prevent the formation of ice crystals inside and outside of the blastocyst increased the survival rate of embryos, but zona hardening during the freezing-thawing processes lowered the hatching rate. Various approaches have been developed to overcome this difficulty [9,17-19]. Partial zona dissection (PZD) using a micropipette handled with a micromanipulator has been used, and is promising in that it allows a wide choice of the dissection range. However, since no perivitelline space is present between the TE and the zona pellucida (ZP), this technique pierce TE cells during the assisted hatching $(\mathrm{AH})$ procedure, which may cause some cells to die. Additionally, the outcomes may vary among operators, and the range of dissection in the ZP has not been standardized. Recently, Strohmer and Feichtinger [20] proposed laser-AH $(\mathrm{LAH})$, in which a hole is made in the ZP with a laser beam in order to complete the $\mathrm{AH}$. In this method, the intensity of the laser beam can be controlled, and it is possible to eliminate some wide portions by successively emitting the laser beam onto the ZP. The present study was conducted to characterize the developmental ability of expanded mouse blastocysts depending on whether $\mathrm{AH}$ was performed before or after vitrification and thawing $(\mathrm{V}-\mathrm{T})$. Another goal of this study was to characterize the effect of $\mathrm{AS}$ and $\mathrm{AH}$ on the cell number in mouse blastocysts, as assessed by differentially staining TE and ICM with a fluorescent stain after 48 hours of cultivation.

\section{Methods}

\section{Embryo preparation}

\section{1) Animals}

ICR mice aged 4 to 5 weeks (female) and 8 to 15 weeks (male) were purchased from the Damool experimental animal center (Daejeon, Korea). All animals were housed with a 12-hour light/dark photoperiod and maintained in an air-conditioned $\left(22^{\circ} \mathrm{C}-25^{\circ} \mathrm{C}\right)$ and humiditycontrolled (40\%-60\%) room.

\section{2) Recovery of 2-cell embryos and culture of expanded blastocysts}

In order to induce superovulation, $7.5 \mathrm{IU}$ of pregnant mare's serum (Sigma, St. Louis, MO, USA) and 7.5 IU of human chorionic gonadotropin (hCG, Sigma) were intraperitoneally injected at an interval of 48 hours. After the injections, female mice were caged with male mice at a 1 to 1 ratio. Females were observed for the presence of a vaginal plug 12 hours later. Females with a vaginal plug were selected and used in this experiment. Animals were sacrificed by cervical dislocation 44 to 48 hours after hCG injection. The oviducts were surgically removed under a dissecting microscope. 2-cell embryos were collected by flushing with the oviducts with 1-mL insulin syringe filled with Ham's F-10 (11-090-1K, Biological Industries, NY, USA) supplemented with 10\% serum substitute supplement (Irvine Scientific, Santa Ana, CA, USA), and cultured in a 60-mm culture dish (3002, Falcon, Santa Ana, CA, USA) with 50- $\mu \mathrm{L}$ of cleavage medium (COOK, Queensland, Australia). A drop of mineral oil (M-3516, Sigma) was used to cover the culture. The embryos were cultured in an incubator for 48 hours at $37^{\circ} \mathrm{C}$ and $6 \% \mathrm{CO}_{2}$. Expanded blastocysts with a clearly distinguishable ICM and TE were recovered, and randomly allocated into the experimental groups. The expanded blastocysts were placed into two groups. In one group, AS was not conducted (control; nontreatment), and the others were treated with AS. The AS group was further divided into the following subgroups, based on various combinations of $\mathrm{V}-\mathrm{T}, \mathrm{AH}$, cross-mechanical $\mathrm{AH}(\mathrm{CMAH})$, and quarter-laser zona thinning-AH (qLZT-AH): AS/N-T/non-AH (group $A$, not treated with $A S$ after thawing), AS/N-T/cMAH (group $B$, treated with $c M A H$ ), AS/V-T/qLZT-AH (group C, treated with qLZT-AH), AS/cMAH/V-T (group $D, C M A H$ was performed before freezing and thawing), and AS/qLZT-AH/N-T (group E, treated with AS and qLZT-AH before freezing and thawing) (Figure 1).

\section{Artificial shrinkage}

After a drop containing $50-\mu \mathrm{L}$ of blastocyst medium (BM, COOK) was placed in the center of the culture dish $(60 \mathrm{~mm}$ in diameter) and covered with mineral oil, it was preincubated for more than 6 hours at $37^{\circ} \mathrm{C}$ and $6 \% \mathrm{CO}_{2}$. Using a micromanipulator (TE2000-U, Nikon, Tokyo, Japan) equipped with an inverted phase-contrast microscope, holding pipette (Sunlight Medical, Jacksonvile, FL, USA), and partial zona dissection pipettes $\left(30^{\circ}\right.$; Sunlight Medical), with tips oriented parallel to each other. AS was carried out in order to artificially dehydrate the blastocoel by piercing through the TE in the ICM, which was oriented to face 12 o'clock.

\section{Assisted hatching \\ 1) Cross-mechanical $\mathrm{AH}$}

The preparation of the medium and pipettes was the same as in AS. The dissected portion by dissected according to the AS protocol was placed in the 6 o'clock position, fixed with a holding pipette, turned $90^{\circ}$, and dissected in the shape of 'a plus sign', which indicated cruciate thinning of the zona.

\section{2) Quarter-laser zona thinning-AH}

LAH was performed under an inverted phase-contrast microscope ( $\times 40)$, which was attached to an RI Saturn 5 Active Laser and Display (B19940, Samsung, Suwon, Korea). The LAH system had a resolution of $1,600 \times 1,200$, and it was possible to make a hole with a short wavelength of $1480 \mathrm{~nm} / 400 \mathrm{~mW}$, corresponding to the full laser 


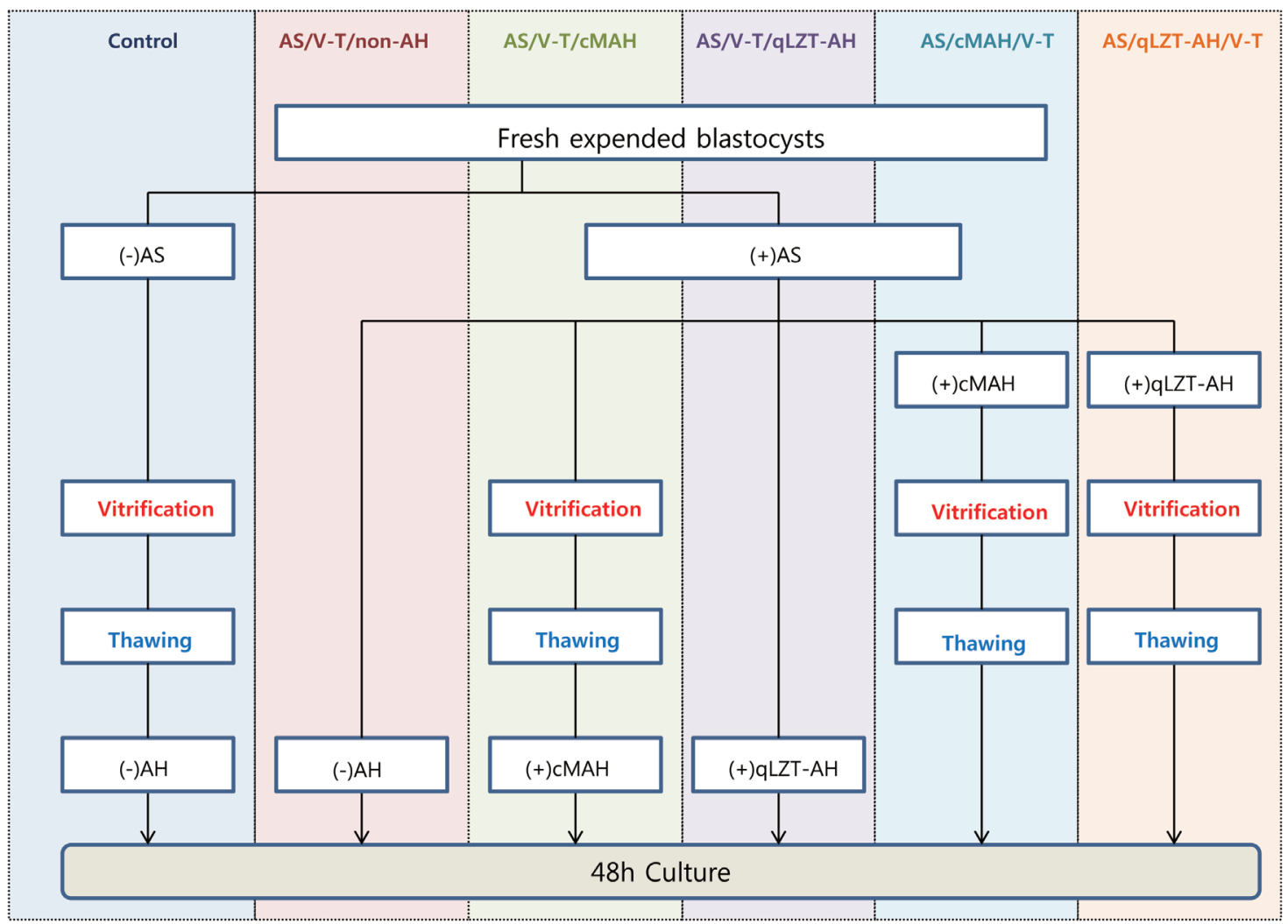

Figure 1. Schematic flow chart for this study. AS, artificial shrinkage; V-T, vitrification and thawing; AH, assisted hatching; $c M A H$, cross-mechanical AH; qLZT-AH, quarter-laser zona thinning-AH. Control, vitrified and thawed blastocysts without AS or AH; AS/N-T/non-AH, vitrified after AS without AH; AS/N-T/CMAH, vitrified and thawed after AS with subsequent CMAH; AS/N-T/qLZT-AH, vitrified and thawed after AS with qLZT-AH; AS/CMAH/V-T, vitrified and thawed after AS and cross-mechanical AS; AS/qLZT-AH/N-T, vitrified and thawed after AS and qLZT-AH; (-)AS, nonAS; (+) AS, AS was carried out; (-) AH, non-AH; (+) cMAH, cross-mechanical AH.

power routinely used in the image plane and reducing the deformation caused by heat. qLZT-AH was performed after 5 to 10 blastocysts were placed in a drop $50-\mu \mathrm{L}$ of BM in a $60-\mathrm{mm}$ incubation dish. While observing the blastocysts on the monitor, a virtual line was drawn on the outer rim of the ZP and shaped according to the curved of the ZP. A laser beam was sequentially emitted along this line to make the entire ZP 25\% thinner. The average number of emissions was 20 to 30 and the size of the laser holes was 3 to $5 \mu \mathrm{m}$. The perforations were located between the center of the ZP and the outer line. Approximately $70 \%$ was removed.

\section{Vitrification and thawing}

All V-T procedures were conducted at room temperature $\left(24^{\circ} \mathrm{C}-\right.$ $26^{\circ} \mathrm{C}$ ). The plain medium used for blastocysts was Dulbecco's phosphate-buffered saline supplemented with $10 \%$ serum substitute supplement. The blastocysts were transferred into vitrification solution 1, which was mixed with plain medium containing $7.5 \%$ ethylene glycol and $7.5 \%$ dimethyl sulfoxide (DMSO) for 10 minutes and then transferred into vitrification solution 2 and mixed with plain medium containing $15 \%$ ethylene glycol, $15 \%$ DMSO, and $0.5 \mathrm{M}$ sucrose 1 minute. Embryos less than seven were loaded into a pull-andcut straw and then cryopreserved in liquid nitrogen. For thawing, the recovered embryos were treated with thawing solution mixed with 1 $\mathrm{M}$ sucrose (thawing solution 1 ) and $0.5 \mathrm{M}$ sucrose (thawing solution 2) in plain medium for 1 and 3 minutes, respectively. The embryos were then twice incubated in plain medium for 5 minutes, followed by washing with blastocyst incubation medium, which was incubation 4 hours at $37^{\circ} \mathrm{C}$ in $6 \% \mathrm{CO}_{2}$.

\section{Double fluorescence staining of blastocysts}

In order to stain the TE cells, solution 1 was prepared by mixing 100 $\mu \mathrm{g} / \mathrm{mL}$ of propidium iodide (P-4170, Sigma) and 1\% Triton X-100 (T93443, Sigma) in Ham's F-10 solution. Solution 2 was a mixture of 25 $\mu \mathrm{g}$ of bisbenzimide (B-2261, Sigma) in $99.9 \%$ ethanol, which was prepared to stain the ICM. In order to carry out double fluorescence staining, the blastocysts were stained in solution 1 for 10 seconds and transferred to solution 2 for 2 hours or more at $4^{\circ} \mathrm{C}$. The stained blastocysts were washed with glycerol (G2025, Sigma) and put onto 

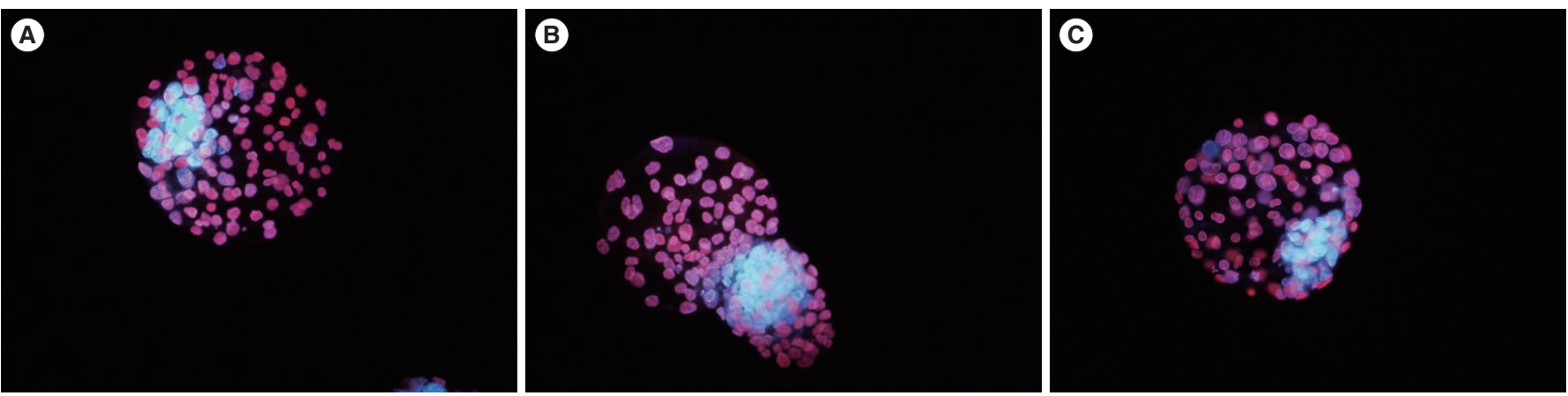

Figure 2. Photograph of cells differentially stained in mouse blastocysts (scale bars, $50 \mu \mathrm{m} ; \times 400$; inner cell mass, blue; trophectoderm, pink). (A) Differential staining of an expanded blastocyst after thawing. (B) Differential staining of a hatching blastocyst, on which quarter-laser zona thinning- assisted hatching (qLZT-AH) was performed, 48 hours after thawing. (C) Differential staining of a hatched blastocyst, on which qLZTAH was performed, 48 hours after thawing.

Table 1. The effect of artificial shrinkage and assisted hatching before and after vitrification and thawing on the development of expanded mouse blastocyst

\begin{tabular}{|c|c|c|c|c|c|c|c|c|c|}
\hline \multirow{3}{*}{ Group } & \multirow{3}{*}{$\begin{array}{c}\text { No. of } \\
\text { examinations }\end{array}$} & \multirow{3}{*}{$\begin{array}{c}\text { No. of } \\
\text { thawed } \\
\text { blastocysts }\end{array}$} & \multicolumn{7}{|c|}{ Embryos developed } \\
\hline & & & \multirow{2}{*}{$\begin{array}{l}\text { No. of surviving } \\
\text { embryos }\end{array}$} & \multicolumn{3}{|c|}{ Blastocysts at $24 \mathrm{hr}$} & \multicolumn{3}{|c|}{ Blastocysts at $48 \mathrm{hr}$} \\
\hline & & & & Blastocysts & $\begin{array}{l}\text { Hatching } \\
\text { Blastocysts }\end{array}$ & $\begin{array}{l}\text { Hatched } \\
\text { blastocysts }\end{array}$ & $\begin{array}{l}\text { Degenerated } \\
\text { blastocysts }\end{array}$ & $\begin{array}{l}\text { Hatching } \\
\text { blastocysts }\end{array}$ & $\begin{array}{l}\text { Hatched } \\
\text { blastocysts }\end{array}$ \\
\hline Control & 6 & 72 & $\begin{array}{c}58 \\
(80.6)^{\mathrm{b})}\end{array}$ & $\begin{array}{c}13 \\
\left(22.4^{\mathrm{a}} \pm 9.7\right)\end{array}$ & $\begin{array}{c}28 \\
\left(38.9^{c)} \pm 18.8\right)\end{array}$ & $\begin{array}{c}17 \\
\left(23.6^{\mathrm{b}, \mathrm{c}} \pm 16.2\right)\end{array}$ & $\begin{array}{c}3 \\
\left(4.2^{\mathrm{a}, \mathrm{b}} \pm 7.0\right)\end{array}$ & $\begin{array}{c}13 \\
\left(18.1^{\mathrm{c})} \pm 13.4\right)\end{array}$ & $\begin{array}{c}42 \\
\left(58.3^{\text {b) }} \pm 9.1\right)\end{array}$ \\
\hline A & 6 & 75 & $\begin{array}{c}71 \\
(94.7)^{\mathrm{a})}\end{array}$ & $\begin{array}{c}13 \\
\left(18.3^{a} \pm 16.0\right)\end{array}$ & $\begin{array}{c}48 \\
\left(64.0^{b)} \pm 20.6\right)\end{array}$ & $\begin{array}{c}10 \\
\left(13.3^{c)} \pm 10.5\right)\end{array}$ & $\begin{array}{c}11 \\
\left(14.7^{\text {a) }} \pm 19.0\right)\end{array}$ & $\begin{array}{c}18 \\
\left(24.0^{\mathrm{b}, c)} \pm 19.3\right)\end{array}$ & $\begin{array}{c}42 \\
\left(56.0^{\mathrm{b}} \pm 18.7\right)\end{array}$ \\
\hline B & 6 & 56 & $\begin{array}{c}56 \\
(100.0)^{a)}\end{array}$ & $\begin{array}{c}0 \\
\left(0.0^{c)} \pm 0\right)\end{array}$ & $\begin{array}{c}45 \\
\left(80.4^{\mathrm{a})} \pm 7.9\right)\end{array}$ & $\begin{array}{c}11 \\
\left(19.6^{c)} \pm 7.9\right)\end{array}$ & $\begin{array}{c}5 \\
\left(8.9^{\mathrm{a}, \mathrm{b})} \pm 6.4\right)\end{array}$ & $\begin{array}{c}33 \\
\left(58.9^{\mathrm{a})} \pm 14.4\right)\end{array}$ & $\begin{array}{c}18 \\
\left(32.1^{\mathrm{c}} \pm 10.7\right)\end{array}$ \\
\hline C & 6 & 71 & $\begin{array}{c}67 \\
(94.4)^{a)}\end{array}$ & $\begin{array}{c}4 \\
\left(6.0^{b, c)} \pm 4.4\right)\end{array}$ & $\begin{array}{c}36 \\
\left(50.7^{\mathrm{b}, \mathrm{c}} \pm 8.0\right)\end{array}$ & $\begin{array}{c}27 \\
\left(48.0^{\mathrm{b})} \pm 5.4\right)\end{array}$ & $\begin{array}{c}6 \\
\left(8.5^{\mathrm{a}, \mathrm{b}} \pm 9.1\right)\end{array}$ & $\begin{array}{c}12 \\
\left(16.9^{c)} \pm 7.3\right)\end{array}$ & $\begin{array}{c}49 \\
\left(69.0^{\text {b) }} \pm 4.8\right)\end{array}$ \\
\hline D & 6 & 62 & $\begin{array}{c}62 \\
\left.(100.0)^{a}\right)\end{array}$ & $\begin{array}{c}5 \\
\left(8.1^{\mathrm{a}, \mathrm{b}} \pm 8.9\right)\end{array}$ & $\begin{array}{c}45 \\
\left(72.6^{\mathrm{a}, \mathrm{b})} \pm 14.5\right)\end{array}$ & $\begin{array}{c}12 \\
\left(19.4^{\mathrm{c})} \pm 10.9\right)\end{array}$ & $\begin{array}{c}6 \\
\left(9.7^{a, b)} \pm 12.0\right)\end{array}$ & $\begin{array}{c}21 \\
\left(33.9^{\mathrm{b})} \pm 13.5\right)\end{array}$ & $\begin{array}{c}35 \\
\left(56.5^{\mathrm{b})} \pm 20.5\right)\end{array}$ \\
\hline $\mathrm{E}$ & 6 & 78 & $\begin{array}{c}77 \\
(98.7)^{a)}\end{array}$ & $\begin{array}{c}1 \\
\left(1.3^{b, c)} \pm 3.5\right)\end{array}$ & $\begin{array}{c}14 \\
\left(18.0^{d)} \pm 12.6\right)\end{array}$ & $\begin{array}{c}62 \\
\left(79.5^{\mathrm{a})} \pm 13.9\right)\end{array}$ & $\begin{array}{c}2 \\
\left(2.6^{b)} \pm 4.6\right)\end{array}$ & $\begin{array}{c}3 \\
\left(3.9^{\text {d) }} \pm 5.2\right)\end{array}$ & $\begin{array}{c}72 \\
\left(92.3^{\text {a) }} \pm 7.1\right)\end{array}$ \\
\hline
\end{tabular}

Values are presented as number (\%) or mean \pm standard deviation.

Control, vitrified and thawed blastocysts without artificial shrinkage or assisted hatching; A, vitrified after artificial shrinkage without assisted hatching; B, vitrified and thawed after artificial shrinkage with subsequent cross mechanical assisted hatching; $C$, vitrified and thawed after artificial shrinkage with subsequent quarter-laser zona thinning-assisted hatching; D, vitrified and thawed after artificial shrinkage and cross-mechanical assisted hatching; $\mathrm{E}$, vitrified and thawed after artificial shrinkage and quarter-laser zona thinning assisted hatching.

${ }^{\text {a-d) }}$ Statistically significant difference $(p<0.05)$.

a slide glass for observation under a fluorescence microscope (BX50, Olympus, Japan) (Figure 2).

\section{Statistical analysis}

The survival rates of the blastocysts and the rates of formation of hatched blastocysts were expressed as percentages. The data were collected in Microsoft Office Excel 2007, and the chi-squared test was used to analyze discontinuous variables and standard errors as well as to compare the number of blastocysts between groups. A $p$-value of less than 0.05 was considered to indicate statistical significance.

\section{Results}

\section{Effects of AS and AH on the development of blastocysts after V-T}

The survival rates of blastocysts in the CMAH and qLZT-AH groups, which were treated before vitrification and after thawing, as well as their developmental rate 48 hours after thawing, are presented in Table 1. The survival rates after thawing in the experimental groups $(A$, 94.7\%; B, 100\%; C, 94.4\%; D, 100\%; E, 98.7\%) were significantly higher than in the control group (80.6\%) $(p<0.05)$. The rate of blastocyst formation during hatching was the highest in group B (AS/V-T/ 
Table 2. Cell numbers of vitrified blastocysts according to artificial shrinkage and assisted hatching

\begin{tabular}{|c|c|c|c|c|c|c|}
\hline \multirow{2}{*}{ Group } & \multirow{2}{*}{$\begin{array}{c}\text { No. of } \\
\text { examined blastocysts }\end{array}$} & \multirow{2}{*}{$\begin{array}{c}\text { No. of } \\
\text { stained blastocysts }\end{array}$} & \multicolumn{3}{|c|}{ Means \pm standard deviation } & \multirow{2}{*}{ ICM (\%) } \\
\hline & & & ICM & TE & Total & \\
\hline Control & 55 & 41 & $21.4^{\mathrm{a})} \pm 7.3$ & $77.9^{\mathrm{a})} \pm 17.5$ & $99.3^{\mathrm{a})} \pm 18.3$ & $21.5^{\mathrm{b})} \pm 7.0$ \\
\hline$A$ & 60 & 41 & $21.9^{\mathrm{a})} \pm 7.5$ & $69.5^{\mathrm{b}, \mathrm{c}} \pm 18.2$ & $91.4^{\mathrm{b})} \pm 21.6$ & $24.0^{\mathrm{a}, \mathrm{b})} \pm 7.1$ \\
\hline B & 51 & 39 & $20.6^{\mathrm{a})} \pm 7.1$ & $72.2^{\mathrm{a}, \mathrm{b}} \pm 17.5$ & $92.8^{\mathrm{a}, \mathrm{b})} \pm 18.8$ & $22.2^{\mathrm{b}, \mathrm{c}} \pm 7.0$ \\
\hline C & 61 & 47 & $17.1^{\mathrm{b})} \pm 5.0$ & $46.8^{\mathrm{d})} \pm 15.2$ & $64.0^{\mathrm{d})} \pm 14.9$ & $26.8^{\mathrm{a})} \pm 9.0$ \\
\hline $\mathrm{D}$ & 56 & 37 & $16.3^{b)} \pm 3.9$ & $59.8^{c)} \pm 13.9$ & $76.2^{c)} \pm 15.9$ & $21.4^{c)} \pm 4.6$ \\
\hline $\mathrm{E}$ & 75 & 53 & $16.5^{\mathrm{b})} \pm 5.2$ & $56.0^{c)} \pm 13.7$ & $72.5^{c)} \pm 15.4$ & $22.8^{\mathrm{b}, \mathrm{c}} \pm 6.2$ \\
\hline
\end{tabular}

ICM, inner cell mass; TE, trophectoderm; Control, vitrified and thawed blastocysts without artificial shrinkage or assisted hatching; A, vitrified after artificial shrinkage without assisted hatching; B, vitrified and thawed after artificial shrinkage, with subsequent cross mechanical assisted hatching; $C$, vitrified and thawed after artificial shrinkage with subsequent quarter-laser zona thinning-assisted hatching; $D$, vitrified and thawed after artificial shrinkage and cross-mechanical assisted hatching; $\mathrm{E}$, vitrified and thawed after artificial shrinkage and quarter-laser zona thinning assisted hatching.

${ }^{\text {a-d) }}$ Statistically significant difference $(p<0.05)$.

CMAH) at 24 and 48 hours after thawing. The rate of hatched blastocyst formation was significantly higher in group $\mathrm{E}(79.5 \%, 92.3 \%)$ than in the other groups (control, 23.6\%:58.3\%; A, 13.3\%:56\%; B, 19.6\%:32.1\%; C, 48\%:69\%; D, 19.4\%:56.5\%) at 24 and 48 hours after thawing $(p<0.05)$.

\section{Effects of $A S$ and $A H$ on the cell number of blastocysts after V-T}

Table 2 summarizes the ratios of the cell number of the ICM to the total blastocyst and TE cell numbers in double fluorescence-stained hatching and hatched blastocysts after the CMAH and qLZT-AH procedures were carried out before vitrification, and after 48 hours of postcultivation. In the present experiment, embryos that were lost during the staining procedures, stained singly, or stained in an overlapped position with fuzzy borders were discarded, resulting in a total number of 258 embryos, instead of 358 . The cell numbers in the ICM of the stained blastocysts were significantly higher in the control group (21.4 \pm 7.3$)$, and group A (21.9 \pm 7.5$)$, and group B (20.6 \pm 7.1$)$ than in other groups $(C, 17.1 \pm 5.0 ; D, 16.3 \pm 3.9 ; E, 16.5 \pm 5.2)(p<0.05)$. Additionally, the number of cells in the TE and the total cell number were higher in the control group (77.9 $\pm 17.5: 99.3 \pm 18.3)$ than in the other groups $(A, 69.5 \pm 18.2: 91.4 \pm 21.6 ; B, 72.2 \pm 17.5: 92.8 \pm 18.8 ; C$, $46.8 \pm 15.2: 64 \pm 14.9 ; D, 59.8 \pm 13.9: 76.2 \pm 15.9 ; E, 56 \pm 13.7: 72.5$ \pm 15.4 ). The ratio of the cells in the ICM to the total cell number was higher in group C $(26.8 \pm 9.0)$ than in the other groups (control, $21.5 \pm 7.0 ; A, 24 \pm 7.1 ; B, 22.2 \pm 7.0 ; D, 21.4 \pm 4.6 ; E, 22.8 \pm 6.2$.

\section{Discussion}

Unlike early blastocysts, expanded blastocysts have a large cavity filled with fluid, known as a blastocoel. For this reason, an additional dehydration procedure is needed to remove this fluid during thaw- ing. Studies on AS and cooling velocity have been conducted to overcome this issue. Vanderzwalmen et al. $[16,17]$ reported that AS after dehydration of the blastocoel using a glass micropipette smaller in diameter than the embryo increased the pregnancy rate after cryopreservation by $20 \%$. They also reported that the pregnancy rates were increased by $38 \%$ and $19 \%$, respectively, in experimental groups with and without the $\mathrm{AH}$ technique, which involves by partial zona dissection after AS with a glass micropipette that penetrates the blastocyst. Son et al. [18] reported that the survival and pregnancy rates were increased by $90 \%$ and $48 \%$, respectively, by cryopreservation and thawing after partial zona dissection of the blastocyst using a 29-gauge needle in the 6 o'clock or 12 o'clock position of the ICM, followed by AS and AH. Additionally, Jo et al. [21] reported that the survival rates of cryopreserved blastocysts after AS were $98 \%$ and $92 \%$ with and without $\mathrm{AH}$, respectively, while the survival rates of cryopreserved blastocysts without AS were $54 \%$ and $58 \%$ with and without $\mathrm{AH}$, respectively. This led to the conclusion that $\mathrm{AS}$ is an efficient method for increasing the viability rate after the cryopreservation of mouse blastocysts, regardless of AH. In the present study, the survival rates of blastocysts that underwent AS and AH both before and after cryopreservation- and thawing were higher than the survival rates of the blastocysts in the control group AS and AH (Table 1). When compared to the effect of AS on the likelihood of pregnancy associated with cryopreserved and thawed embryos reported by Tucker et al. [22], Check et al. [23], and Tao and Tamis [15], the pregnancy rates in the groups with and without AH were $28 \%$ vs. $15 \%$, $30.4 \%$ vs. $15.2 \%$, and $24 \%$ vs. $0 \%$, respectively. These results mean that $\mathrm{AH}$ may have a positive impact on the pregnancy rate. Jo et al. [21] reported that the hatching rates associated with AH using the PZD method were $96 \%$ and $34 \%$ in the groups with and without AS, respectively. The hatching rates of the groups with and without $\mathrm{AH}$ after AS were $100 \%$ and $41 \%$, respectively. A high hatching rate was 
found after $\mathrm{AH}$ in cryopreserved and thawed blastocyst embryos $(p<0.01)$, and they concluded that $\mathrm{AH}$ was an effective method for improving the hatching rate. Cieslak et al. [24] reported that a pregnancy rate of $42.0 \%$ was obtained in a group that underwent threedimensional partial zona dissection, using a micropipette rather than strong acid for dissecting the ZP in preimplantation genetic diagnosis and $\mathrm{AH}$, which was then rotated for another round of dissection, compared to a rate of $33.3 \%$ in the control group. Additionally, Park et al. [25] showed that the rate of fully hatched embryos cultivated for 72 hours after AS was $9.0 \%$ in the group in which cMAH was performed, compared to $0 \%$ in the group in which single mechanical $\mathrm{AH}$. The present experiment was largely based on the report of Khalifa et al. [26], who found a high incidence of hatched blastocyte embryo formation using quarter-LAH (qLAH) and qLZ-AH, which are helpful techniques for encouraging blastocysts to hatch because they eliminate the rather large area of the ZP. The rates of hatched blastocyst formation were $49.1 \%$ and $40.4 \%$ in the qLAH and qLZT$\mathrm{AH}$ groups, respectively, which were significantly higher than in the groups which a smaller area of the ZP was eliminated. Their study was referenced by Park et al. [25], who found a significantly higher rate of formation of hatched blastocysts after 72 hours of culture in the qLAH and qLZT-AH groups than in the control groups. In the present study, the rate of hatched blastocyst embryos was consistently the highest in the AS/qLZT-AH/N-T group (Table 1).

According to Thouas et al. [27] the cell numbers of the ICM and TE and the total cell numbers of 2-cell mouse embryos were $21 \pm 2$, $55 \pm 4$, and $75.3 \pm 3$, respectively, after 72 hours of cultivation. The cell number in the ICM of the control group was similar to that found in this study (21.4 \pm 7.3$)$, however, some discrepancies were present in the cell number of the TE $(77.9 \pm 17.5)$ and in the total cell number $(99.3 \pm 18.3)$ (Table 2). It has been reported that faster embryonic development leads to the formation more cells and a higher ratio of the ICM to total cells [28]. However, Park et al. [25] reported that the formation rate of the hatched blastocyst embryos in the qLZT-AH group was higher than what was observed in the cMAH group $(p<0.05)$. They argued that the improved hatching results were not due to the large cell number because the number of cells in the TE was low. In the present study, the formation rate of hatched blastocyst embryos in the AS/qLZT-AH/N-T group, which underwent cryopreservation after AS and qLZT-AH, was the highest among all experimental groups. However, in this group, the cell number of the ICM and TE and the total cell number were low, similar to the results of Park et al. [25] (Table 2). Lane et al. [29] reported that the cell number of the TE was similar to that of the blastocysts regardless of the implantation technique, as well as no correlation between the number of cells in the TE and the implantation rate in mouse blastocyst embryos. Richter et al. [30] reported that the implantation rate did not vary with the size of the blastocyst, the number of cells in the TE, or the size and shape of ICM, and only varied according to the external shape of the embryo. In the present study, the survival rate of blastocyst embryos after thawing was significantly different depending on whether AS before cryopreservation, but the hatching rate was similar.

The highest formation rate of expanded blastocysts was achieved by performing the AS and qLZT-AH procedures before vitrification, followed by 48 hours of cultivation. The next highest formation rates were observed after the $\mathrm{CMAH}$ procedure, in $\mathrm{AS}$ and $\mathrm{AH}$ were performed with a micropipette, and the qLZT-AH procedure, which used a laser before V-T. The cell number of in the ICM and TE and the total cell count were significantly higher in the control group, in which AS and $\mathrm{AH}$ were not performed, than in other groups. With regard to the above results, AS and qLZT-AH procedures performed before cryopreservation are known to have beneficial effects on embryonic development. With this in mind, further studies are needed regarding the timing and methodologies of $\mathrm{AH}$ in embryo transfer procedures involving cryopreservation and thawing.

\section{Conflict of interest}

No potential conflict of interest relevant to this article was reported.

\section{References}

1. Gardner DK, Schoolcraft WB, Wagley L, Schlenker T, Stevens J, Hesla J. A prospective randomized trial of blastocyst culture and transfer in in-vitro fertilization. Hum Reprod 1998;13:3434-40.

2. Jones GM, Trounson AO, Gardner DK, Kausche A, Lolatgis N, Wood C. Evolution of a culture protocol for successful blastocyst development and pregnancy. Hum Reprod 1998;13:169-77.

3. Cohen J, Elsner C, Kort H, Malter H, Massey J, Mayer MP, et al. Impairment of the hatching process following IVF in the human and improvement of implantation by assisting hatching using micromanipulation. Hum Reprod 1990;5:7-13.

4. Bonsi A. Blastocyst transfer and freezing: can this help us to improve the success of assisted reproduction? Singapore J Obstet Gynecol 1995;26:13-7.

5. Cho HJ, Yoon SH, Yoon HG, Lee WD, Lee SW, Lee SG, et al. Viable high pregnancies obtained from frozen-thawed blastocysts: experience of more than 350 transfer cycles. Korean J Reprod Med 1997:55-6.

6. Menezo Y, Nicollet B, Herbau N, Andre D. Freezing co-cultured humanblastocysts. Fertil Steril 1992;58: 977-80.

7. Kaufman RA, Menezo Y, Hazout A, Nicollet B, DuMont M, Servy EJ. Cocultured blastocyst cryopreservation: experience of more than 500 transfer cycles. Fertil Steril 1995;64:1125-9. 
8. Nakayama T, Goto Y, Kanzaki H, Takabatake K, Himeno T, Takakura K, et al. Cryopreservation of human blastocyst. Proceedings of the IX world congress on in vitro Fertilization and Alternated Assisted Reproduction; 1995 April 3-7; Vienna, Austria. p. 451-4.

9. Zhu SE, Kasai M, Otoge H, Sakurai T, Machida T. Cryopreservation of expanded mouse blastocysts by vitrification in ethylene glycol-based solutions. J Reprod Fertil 1993;98:139-45.

10. Scheffen B, Vanderzwalmen P, Massip A. A simple and efficientprocedure for preservation of mouse embryos by vitrification. Cryo Letters 1986;7:260-9.

11. Miyake T, Kasai M, Zhu SE, Sakurai T, Machida T. Vitrification of mouse oocytes and embryos at various stages of development in an ethylene glycol-based solution by a simple method. Theriogenology 1993;40:121-34.

12. Carroll J, Depypere H, Matthews CD. Freeze-thaw-induced changes of the zona pellucida explains decreased rates of fertilization in frozen-thawed mouse oocytes. J Reprod Fertil 1990;90: 547-53.

13. Germond M, Senn A, Rink K, Delacretas G, De Grandi P. Is assisted hatching of frozen-thawed embryos enhancing pregnancy outcome in patients who had several previous indationfailures? J Reprod Fertil 1995;3:41-2.

14. Cohen J. Assisted hatching of human embryos. J In Vitro Fert Embryo Transf 1991;8:179-90.

15. Tao J, Tamis R. Application of assisted hatching for 2-day-old, frozen-thawed embryo transfer in a poor-prognosis population. J Assist Reprod Genet 1997;14:128-30.

16. Vanderzwalmen P, Bertin G, Debauche C, Standaert V, van Roosendaal $E$, Vandervorst $M$, et al. Births after vitrification at morula and blastocyst stages: effect of artificial reduction of the blastocoelic cavity before vitrification. Hum Reprod 2002;17:744-51.

17. Vanderzwalmen P, Bertin G, Debauche C, Standaert V, Bollen N, van Roosendaal $E$, et al. Vitrification of human blastocysts with the Hemi-Straw carrier: application of assisted hatching after thawing. Hum Reprod 2003;18:1504-11.

18. Son WY, Yoon SH, Yoon HJ, Lee SM, Lim JH. Pregnancy outcome following transfer of human blastocysts vitrified on electron microscopy grids after induced collapse of the blastocoele. Hum Reprod 2003;18:137-9.
19. Liebermann J, Knopoff E, Matthews J, Erman A, Sanchez S, Tucker M. Blastocyst cryopreservation: to slow-freeze or to vitrify? Fertil Steril 2005;84 Suppl 1:S182.

20. Strohmer H, Feichtinger W. Successful clinical application of laser for micromanipulation in an in vitro fertilization program. Fertil Steril 1992;58:212-4.

21. Jo DH, Ko GR, Jung JH, Choi JR, Joo JK, Lee KS. Effects of the artificial shrinkage and assisted hatching before vitrification on the development of the vitrified mouse expanding blastocysts. Korean J Reprod Med 2008;35:275-83.

22. Tucker MJ, Cohen J, Massey JB, Mayer MP, Wiker SR, Wright G. Partial dissection of the zona pellucida of frozen-thawed human embryos may enhance blastocyst hatching, implantation, and pregnancy rates. Am J Obstet Gynecol 1991;165:341-4.

23. Check JH, Hoover L, Nazari A, O'Shaughnessy A, Summers D. The effect of assisted hatching on pregnancy rates after frozen embryo transfer. Fertil Steril 1996;65:254-7.

24. Cieslak J, Ivakhnenko V, Wolf G, Sheleg S, Verlinsky Y. Three-dimensional partial zona dissection for preimplantation genetic diagnosis and assisted hatching. Fertil Steril 1999;71:308-13.

25. Park SB, Kim HJ, Choi YB, Ahn KH, Lee KH, Yang JB, et al. The effect of various assisted hatching techniques on the mouse early embryo development. Clin Exp Reprod Med 2014;41:68-74.

26. Khalifa EA, Tucker MJ, Hunt P. Cruciate thinning of the zona pellucida for more successful enhancement of blastocyst hatching in the mouse. Hum Reprod 1992;7:532-6.

27. Thouas GA, Korfiatis NA, French AJ, Jones GM, Trounson AO. Simplified technique for differential staining of inner cell mass and trophectoderm cells of mouse and bovine blastocysts. Reprod Biomed Online 2001;3:25-9.

28. Iwasaki S, Yoshiba N, Ushijima H, Watanabe S, Nakahara T. Morphology and proportion of inner cell mass of bovine blastocysts fertilized in vitro and in vivo. J Reprod Fertil 1990;90:279-84.

29. Lane M, Schoolcraft WB, Gardner DK. Vitrification of mouse and human blastocysts using a novel cryoloop container-less technique. Fertil Steril 1999;72:1073-8.

30. Richter KS, Harris DC, Daneshmand ST, Shapiro BS. Quantitative grading of a human blastocyst: optimal inner cell mass size and shape. Fertil Steril 2001;76:1157-67. 